\title{
Born in the USA: a comparison of modals and nominal quantifiers in child language
}

\author{
Vincenzo Moscati ${ }^{1}$ - Jacopo Romoli ${ }^{2}$. \\ Tommaso Federico Demarie ${ }^{3}$. Stephen Crain ${ }^{4}$
}

Published online: 2 February 2016

(C) The Author(s) 2016. This article is published with open access at Springerlink.com

\begin{abstract}
One of the challenges confronted by language learners is to master the interpretation of sentences with multiple logical operators (e.g., nominal quantifiers, modals, negation), where different interpretations depend on different scope assignments. Five-year-old children have been found to access some readings of potentially ambiguous sentences much less than adults do (Lidz and Musolino, Lang Acquis 13(2):73-102, 2006; Musolino, Universal Grammar and the acquisition of semantic knowledge, 1998; Musolino and Lidz, Lang Acquis 11(4):277-291, 2003, among many others). Recently, Gualmini et al. (Nat Lang Semant 16:205-237, 2008) have shown that, by careful contextual manipulation, it is possible to evoke some of the putatively unavailable interpretations from young children. Their proposal is quite general, but the focus of their work was on sentences involving nominal quantifiers and negation. The present paper extends this investigation to sentences with modal expressions. The results of our two experimental studies reveal that, in potentially ambiguous
\end{abstract}

\footnotetext{
$凶$ Jacopo Romoli

jacopo.romoli@gmail.com

Vincenzo Moscati

moscati.v@gmail.com

Tommaso Federico Demarie

tommaso.demarie@gmail.com

Stephen Crain

stephen.crain@mq.edu.au

1 Università degli studi di Siena, Complesso San Niccolò, Via Roma 56, 53100 Siena, Italy

2 School of Communication, Ulster University, Newtownabbey BT37 0QB, UK

3 Singapore University of Technology and Design, 20 Dover Drive, Singapore 138682, Singapore

4 Department of Linguistics, Australian Hearing Hub, Macquarie University, 16 University Avenue, Sydney, NSW 2109, Australia
} 
sentences with modal expressions, the kinds of contextual manipulations introduced by Gualmini and colleagues do not suffice to explain children's initial scope interpretations. In response to the recalcitrant data, we propose a new three-stage model of the acquisition of scope relations. Most importantly, at the initial stage, child grammars make available only one interpretation of negative sentences with modal expressions. We call this the Unique Scope Assignment (USA) stage.

Keywords Language acquisition - Negation - Scope ambiguities - Quantifiers · Modals · Ambiguity resolution

\section{Introduction}

Investigations of how adult language users interpret (potentially) ambiguous sentences provide a unique window into the inner workings of the human sentence processing mechanism, i.e. the parser. Whenever more than one structural analysis is available for the same string of words, the parser's decision about the preferred interpretation shed light on its internal operating principles. Similarly, investigations of the resolution of ambiguities by children are revealing about the acquisition of these operating principles of the parser. In addition, investigations of young children's interpretations of ambiguous sentences can be revealing about the ways in which children's parsing strategies are influenced by context, and by constraints on language learnability.

Our focus in this paper is on ambiguities that arise (at least potentially) in sentences that contain multiple logical operators. Such ambiguities have been extensively investigated in theoretical syntax and semantics (see May 1985; Beghelli and Stowell 1997; Fox 1999; Mayr and Spector 2013, among many others). More recently, these ambiguities involving logical expressions have attracted interest in the field of child language acquisition. To illustrate one of the relevant phenomena under consideration, consider the sentence in (1), which is taken from Musolino (1998). The example contains both negation and a universal nominal quantifier in subject position.

Every horse didn't jump over the fence.

a. Every horse is such that it did not jump over the fence.

b. Not every horse jumped over the fence.

For adult speakers, depending on the context and on intonation, sentence (1) can be assigned either the meaning indicated in (1a) or the meaning in (1b). It is easy to verify that these two readings are associated with different truth conditions. For example, if not every horse jumped over the fence, but some did, then (1a) is false, whereas (1b) is true.

In evaluating sentence (1), adults tend to accept it both in contexts that verify meaning (1a) and in contexts that verify (1b). If child grammar is the same as that of adults, then children too would be expected to accept sentence (1) in both circumstances. Previous studies, however, have suggested that this may not be the case. In particular, Musolino (1998) reported that 5-year-old children tended to reject sentences like (1) in one of the contexts in which adults accept them. More specifically, the Musolino study found that children consistently rejected sentences like (1) as an accurate descrip- 
tion of experimental vignettes that only verified the reading in (1b), whereas adults consistently accepted the same sentences in these experimental contexts. Musolino (1998) interpreted the results as supporting the view that children's grammar initially excludes or "strongly disfavours" the semantic interpretation in (1b). Following the initial study by Musolino, similar results were obtained by other researchers, revealing further asymmetries in the interpretations of ambiguous sentences by children and adults (Musolino et al. 2000; Krämer 2000, among others).

The observed differences between children and adults suggest that children access only a restricted set of the interpretations that adults assign to ambiguous sentences. In addition, some experimental findings have led to the conclusion that the differences between children and adults extend to sentences that are unambiguous for adults. There have been at least two such cases. One involved negative sentences with an existential nominal quantifier, such as (2), which contains negation and the quantifier some.

The detective didn't find some guys.

a. *It is not the case that the detective found some guys.

b. There are some guys that the detective didn't find.

In principle, there are two possible scope assignments for (2), as indicated in (2a) and (2b). For most adult English speakers, however, only the interpretation in (2b) is acceptable: the scope assignment indicated in (2a) is excluded for most adults. (As customary, we have indicated the unacceptability of (2a) with the asterix '*'.) Yet the findings reported in Musolino (1998) suggested that, in contrast with this adult pattern, English-speaking children initially access only the interpretation represented in (2a), the one that is excluded for adults. Based on children's behavioural responses to sentences with nominal quantifiers, as in (1a) and (2), Musolino (1998) and Musolino et al. (2000) observed that children initially assign an isomorphic mapping between surface syntax and semantic interpretation, apparently disallowing inverse scope readings.

A second discrepancy between child and adult behaviour challenges this initial observation of isomorphism. The findings were reported first in Moscati (2008) (see also Gualmini and Moscati 2009; Moscati 2011). In this case, the potential ambiguity involves negative sentences with modals expressing possibility, as in the Italian example in (2).

(3) Il contadino può non dare le carote all'elefante.

The farmer MOD not give the carrots to.the.elephant

a. *The farmer is not allowed to give the carrots to the elephant

b. The farmer is allowed not to give the carrots to the elephant

For adult Italian speakers' grammar, sentence (3) is unambiguous. The only licit interpretation is (3b). The absence of ambiguity follows from the fact that the interpretation of negative sentences with existential modals appears to be dictated by the surface word order of Italian. That is, there are no inverse scope readings in cases like (3). Consequently, the modal potere takes wide scope $(\diamond>\neg)$ when it precedes negation, as indicated in (3b), and the reading (3a) is excluded. Similarly, negation obligatorily 
takes wide scope $(\neg>\diamond)$ when it precedes a modal, as in (4) (see also Moscati and Gualmini 2008). ${ }^{1}$

(4) Il contadino non può dare le carote all'elefante. the farmer not MOD give the carrots to.the.elephant

a. The farmer is not allowed to give the carrots to the elephant

b. *The farmer is allowed not to give the carrots to the elephant

Interestingly, the Moscati study revealed that Italian-speaking children consistently rejected the unique adult reading of (3), i.e., (3b). In contrast to adults, children appeared to assign the 'inverse scope' $(\neg>\diamond)$ reading $(3 \mathrm{a})$, which is unacceptable for adults. Children's interpretation therefore represents, at least prima facie, a challenge to the observation of isomorphism proposed by Musolino (1998): children, in this case, appear to access precisely the inverse scope reading, and this reading only.

The absence of a unified account of children's interpretation of potentially ambiguous sentences has led to reconsideration of a different proposal, one which had been advanced in Crain et al. (1994) and Crain and Thornton (1988) (see also Moscati and Crain 2014 and Moscati 2013). On this account, learnability constraints dictate children's initial scope preferences for interpreting ambiguous sentences. The proposal is that children always start with the logically strongest interpretation of ambiguous sentences, i.e., the subset reading (see Berwick 1985). This learnability-based account, while controversial, encompasses children's interpretations of all of the examples we have considered so far: (1), (2), and (3). In all three cases, children's initial interpretation corresponds to the strong reading, regardless of surface word order. ${ }^{2}$

These two proposals, while very different, share in common the idea that children initially only have a single reading for the sentences in (1), (2), and (3) and that this reading is not necessarily one that is attested in the local language. Child and adult grammars differ, therefore, in ways that cannot be explained by experiencebased accounts of language development that rely on general learning mechanisms and input frequency as the basis of their non-adult behaviour. In any case, there would seem to be circumstantial evidence for postulating a stage of language acquisition, roughly between the ages of about 3 to 5 years, at which only one scope assignment is possible for children. We call this the Unique Scope Assignment (USA) stage.

The USA has its detractors. In particular, Gualmini et al. (2008) conducted a series of experiments demonstrating the availability of readings that, they contend, were arti-

\footnotetext{
${ }^{1}$ Notice that this behaviour appears completely parallel to that of being allowed in English, as used in the glosses: (i) and (ii) are also unambiguous and can only have the scope interpretation corresponding to the surface order of modal vs. negation.
}

(i) The farmer is allowed not to give carrots to the elephant.

(ii) The farmer is not allowed to give carrots to the elephant.

Italian può, however, is more flexible than being allowed in terms of which modal base interpretation it can have. In glosses for subsequent examples, we will use the English modal that seems to be more appropriate for the relevant interpretation of può in the story.

2 For a thorough discussion of this approach and the arguments for learnability constraints see Gualmini and Schwarz (2009) and Moscati and Crain (2014). 
ficially suppressed in previous studies of children's ambiguity resolution. The research strategy they advise emphasizes the crucial role played by pragmatic factors in evoking interpretations of logically ambiguous sentences that had been, arguably, obscured in earlier research. Careful manipulations of contextual features were shown to assist children in accessing the putatively unavailable readings of sentences like (1), bringing the range of interpretations assigned by children on a par with those of adults. Such results called into question the need to postulate a stage of Unique Scope Assignment (USA), at least in the cases investigated by Gualmini et al. (2008). Instead, the new findings invited the conclusion that multiple readings of ambiguous sentences are available to children as soon as they can be tested.

In the study reported in the present paper, we ask whether the kinds of pragmatic factors discussed in Gualmini et al. (2008) can be generalized to account for the other cases where children have been observed to lack interpretations that are highly salient, in fact unambiguously so for adults. If the research strategy employed by Gualmini and colleagues is up to the task, then we should find that, given appropriate contextual support, children are able to access the readings that have eluded them in previous studies. This should include the surface scope reading of (potentially ambiguous) sentences with nominal quantifiers like (2), as well as the surface scope reading of negative sentences with existential modals in Italian, such as example (3).

More specifically, we report the findings of two experiments investigating sentences like (3) in direct comparison with those like (2), the latter of which were among those tested by Gualmini et al. (2008). The results of both of these new experiments suggest that children's interpretations of sentences with modal expressions should not be assimilated within the Gualmini et al. (2008) account based on nominal quantifiers. The structure of the paper is as follows. The next section introduces the proposal by Gualmini et al. (2008) in more detail, and we spell out the predictions of their account for both modals and nominal quantifiers. Sections 3 and 4 report the findings of our two experiments designed to test these predictions using negative sentences with modal expressions, with Italian-speaking children. In Sect. 5, we discuss the results and articulate a developmental model incorporating a stage of Unique Scope Assignment. In Appendix 1, we present the statistical analysis of the data, and in the process offer a few insights regarding the problem of heteroscedasticity in linguistic experiments.

\section{The Question-Answer Requirement}

After the publication of results indicating children's seeming lack of certain adult interpretations, as summarized above, a series of studies appeared that reversed the conclusions of that earlier research. These studies showed children's sensitivity to contextual factors when interpreting ambiguous sentences; they demonstrated adultlike performance by children in accessing many of the interpretations that had eluded them in previous research. According to the authors of many of these later studies (e.g., Gualmini 2004b, Gualmini 2004a; Krämer 2000; Musolino and Lidz 2006; Gualmini et al. 2008), the cause of children's non-adult behaviour in the earlier work resided in their greater sensitivity to certain discourse-pragmatic factors, as compared to adults. 
Gualmini et al. (2008), in particular, focused on one contextual factor, namely the question that was under consideration in the experimental context presented. Essentially, Gualmini and colleagues draw our attention to the fact that sentences can profitably be analysed as responses to an explicit or implicit question in the conversational context. Building on much previous literature in semantics/pragmatics, they refer to this feature of the context as the Question Under Discussion (QUD) (von Fintel 1994; Roberts 2004; see also Beaver and Clark 2009). Gualmini and colleagues argue that QUDs play a crucial role in promoting and demoting various readings of ambiguous sentences. They capture this intuition in the following principle:

\section{Question-Answer Requirement (QAR):}

The selected interpretation of an ambiguous sentence is required to be a good answer to the Question Under Discussion (QUD).

Let us spell out some of the assumptions that underlie the QAR. First, the QAR is based on a particular analysis of the meaning of questions, and what counts as a good answer to a question. Following Hamblin (1973) and much subsequent work, the meaning of a yes/no-question such as (6a) is taken to be the set that contains (the meanings of) its positive and negative answers, as in (6b). A good answer is any sentence that entails either the proposition corresponding to the positive member of the set, or the one corresponding to its negative member. So, good answers include the sentence John is over there drinking champagne (which entails that John came and thus answers yes to (6a)) as well as the sentence He is in Florida (which entails that John did not come and thus answers no).

$$
\begin{array}{ll}
\text { a. } & \text { Did John come? } \\
\text { b. } & \llbracket \text { Did John come? } \rrbracket= \\
& \left\{\lambda w \llbracket \text { John came } \rrbracket^{w}, \lambda w\left(\neg \llbracket \text { John came } \rrbracket^{w}\right)\right\}
\end{array}
$$

With these basics in hand, we can now return to how the QAR is invoked to explain children's non-adult behaviour in previous research. The proposal is that the readings that proved problematic for children were ones that were not good answers to the Question Under Discussion (QUD) in the story contexts presented to children in previous research. To illustrate, consider the sentence in (7) (repeated from (2) above). Recall that children proved unable to access the reading indicated in (7b) in the study by Musolino (1998). Instead, children appeared to assign a non-adult interpretation to (7), corresponding to (7a).

The detective didn't find some guys.

a. *It is not the case that the detective found some guys.

b. There are some guys that the detective didn't find.

Gualmini et al. (2008) argue that, in the experimental context of that study, the salient (albeit implicit) QUD was whether or not the detective found some of the guys. That is, the QUD was (8). The meaning of this question is rendered in (8b), and schematically in $(8 c)$. 

a. Did the detective find some guys?
b. $\left\{\begin{array}{l}\lambda w \llbracket \text { the detective found some guys } \rrbracket^{w}, \\ \lambda w\left(\neg \llbracket \text { the detective found some guys } \rrbracket^{w}\right)\end{array}\right\}$
c. $\{\exists, \neg \exists\}$

Assuming that, for children, the QUD was (8), we should ask then how children should be expected to interpret the answer in (7). The Question-Answer Requirement predicts that only the reading in (7a) would be accessible, according to which it is not the case that the detective found some guys. This is a good answer to (8), because the meaning in (7a) entails one of the two possible answers to the question in (8), namely the noanswer $(\neg \exists)$. By contrast, the meaning of ( $7 b$ ) should not be accessible to children, according to the QAR. The reason is that the meaning of ( $7 b)$ does not entail either member of the meaning of the question, i.e. it doesn't answer either yes or no to (8a).

According to the QAR, children did not access the interpretation in (7b) in the Musolino (1998) study because the meaning of (7b) was not a good answer to the salient QUD. This immediately predicts that this reading should become available to children if the relevant QUD is made salient. For instance, the QAR predicts that children will be able to access the adult interpretation of (7), i.e., (7b), in circumstances in which the QUD is (9a). In this case, both reading (7a) and (7b) are good answers to $(9 \mathrm{a})$, as they both entail the no-answer $(\neg \forall)$.
a. Did the detective find every guy?
b. $\left\{\begin{array}{l}\lambda w \llbracket \text { the detective found every guy } \rrbracket^{w}, \\ \lambda w\left(\neg \llbracket \text { the detective found every guy } \rrbracket^{w}\right)\end{array}\right\}$
c. $\{\forall, \neg \forall\}$

Indeed, in the three experiments reported in Gualmini et al. (2008), children were shown to access the reading in (7b) when (9) was the salient QUD. Other findings also confirm the QAR, at least for sentences involving negation and nominal quantifiers.

What about adults? Why do adults have more ready access to readings that do not satisfy the QAR? Gualmini and his colleagues propose that two factors are at play in the interpretation of ambiguous sentences, both for children and adults. One is the Question Under Discussion (QUD), and the other is the Principle of Charity, which entreats language users to favour interpretations of ambiguous sentences that make them true in the conversational context (Grice 1975 and much subsequent work). Adults lean more heavily on the Principle of Charity. If the QUD is not answered in the conversational context, the Principle of Charity encourages them to accommodate a different QUD. Gualmini and colleagues suggest that children, in contrast to adults, adhere to the Principle of Charity only if the QUD is answered. In short, their proposal could be described as a two-stage model of development: at the first stage, the QAR outranks the Principle of Charity; at the second stage, the ranking is reversed. ${ }^{3}$

\footnotetext{
3 Notice that invoking different rankings between the QAR and the Principle of Charity is just one way of describing the proposal advanced by Gualmini et al. (2008), and they themselves do not describe their proposal in these terms. An alternative way of thinking about the differences between children and adults could be to invoke the processing difficulty that arises in accommodating a novel QUD. We thank an anonymous reviewer for raising our attention to this point.
} 
Although the two-stage QAR model of acquisition was originally developed to account for the interpretations of negative sentences with nominal quantifiers by children and adults, it is clear that the account is intended to generalize to other combinations of logical operators. More generally, because the QUD account has been formulated in terms of discourse congruence, it generates predictions that extend to any sentence with more than one scope-bearing element, including the potential scope ambiguities generated by logical connectives and modals. We now turn to the case of modals.

\subsection{Modals: a challenge to the Question-Answer Requirement?}

Nominal quantifiers and modals are traditionally treated on a par, both as quantificational expressions. In its simplest version, the idea is that nominal quantifiers quantify over individuals, whereas modals quantify over possible worlds or similar objects (see Portner 2009 and references therein). Nominal quantifiers and modals are also analysed uniformly in the literature on scope interactions. For instance, Fox (2000) and Mayr and Spector (2013) propose economy principles (e.g., Do not shift scope unless the result weakens the meaning!) which would apply equally to modals and nominal quantifiers. In fact, these authors invoke modals to provide evidence in support of such principles:

The interaction of modals and the GSEC [Generalized Scope Economy Condition] raises a number of non-trivial issues, both theoretically and empirically. $[\ldots]$ we describe a number of facts which might seem to be problematic for our proposal, and we show that on closer examination these apparent counterexamples are compatible with the GSEC and in some cases provide additional support for it. (Mayr and Spector 2013, p. 32)

To account for different scope possibilities that are associated with different types of operators, they postulate further constraints in addition to their economy principles (Neg-raising, PPI-hood, etc.).

The analogy between the semantics of modals and that of nominal quantifiers, combined with the very general formulation of the QAR given in (5), constitutes our main motivation for comparing the effects of the QAR with both types of operators.

The first study explicitly investigating the role of the QUD in modal interpretation is the one reported in Moscati (2011), to which we turn now. The stimulus sentences of this study included examples such as (3), repeated as (11) below. Recall that children were reported to initially access only a non-adult-interpretation of (11), represented in (11a). Children failed to access the unique interpretation available to adults, indicated in (11b).

(11) Il contadino può non dare le carote all'elefante the farmer MOD not give the carrots to.the.elephant

a. *The farmer is not allowed to give the carrots to the elephants

b. The farmer is allowed not to give the carrots to the elephants 
According to the QAR, children should be able to access the reading in (11b) if they are provided with an appropriate QUD. To test this, Moscati introduced an explicit QUD on each test trial, manipulating whether (11b) was a good answer to the QUD in the experimental context. First, he arranged that only the reading associated with (11b) was a 'true' description of the events that had unfolded on each experimental trial. Therefore, children's acceptances of the target sentences were taken as evidence that they assigned the adult interpretation, such as (11b), whereas children's rejections were taken as evidence that they had assigned a non-adult reading, such as (11a). The novel experimental manipulation in the study, however, involved the QUD. There were two conditions. In one of them, Condition 1, the reading that made the sentence true, e.g. (11b), was not a good answer to the QUD. According to the QAR, children should not access this reading in this condition, and should reject the test sentences. Condition 1 is illustrated in (12). Notice that interpretation (11b), on which the farmer is allowed not to give the carrots to the elephant $(\diamond \neg)$, does not answer (12) - it does not entail either the positive or the negative member of the meaning of (12), indicated in $(12 a)$.

Può il contadino dare le carote all'elefante?

Can the farmer give the carrots to.the.elephant?

a. $\{\diamond, \neg \diamond\}$

In the second condition, by contrast, the same interpretation (11b) did answer the QUD. Example (13) illustrates Condition 2.

$$
\begin{aligned}
& \text { Deve il contadino dare le carote all'elefante? } \\
& \text { Must the farmer give the carrots to.the.elephant? }
\end{aligned}
$$

a. $\{\square, \neg \square\}$

To summarize, everything but the QUD was held constant across trials. The QAR led to two predictions. First, children were expected to reject the target sentences in Condition 1, where the only true reading of the test sentences is not felicitous (i.e., does not answer the QUD). Second, children were expected to accept the target sentences in Condition 2, where there is a reading that is both felicitous and true in the context.

The critical observation is that question (13) is answered by sentence (11), on interpretation (11b). This is because it is possible that 'The farmer doesn't give the carrots to the elephant' $(\diamond \neg)$ entails the negative member of the meaning of question (13). This sentence entails that it is not necessary that the farmer give carrots to the elephant $(\neg \square)$. According to the QAR, therefore, children should access this interpretation, and should accept test sentence (11).

Despite careful manipulation of the QUD, Moscati (2011) found no evidence of an effect of the QUD across the two conditions. Children consistently rejected the target sentences in both conditions. The results reported in Moscati (2011) represent, therefore, a challenge for the QAR model. At this point one could reasonably ask whether children's rejection of (11) is due to a misinterpretation of the modal può. In particular, one could hypothesise that children are confusing può with its universal 
counterpart deve. ${ }^{4}$ If so, sentence (11) would be assigned a surface scope interpretation, with the meaning that the farmer must not give carrots to the elephants. Because such an interpretation is incompatible with the context, this could be the source of children's rejections. ${ }^{5}$ This scenario is unlikely, however, in view of previous findings in the literature which have shown that, by age 5, children have become sensitive to the different forces conveyed by different modal expressions. For example, Hirst and Weil (1982) used a forced-choice task to investigate 5-year-old children's ability to discriminate between modals on the basis of their quantificational force. In the experimental paradigm, children heard a sequence of minimal pairs of statements produced by two puppets. These statements differed only in the modal: for example, The peanut must be under the cup versus The peanut may be under the cup. The child participants consistently used the puppets' statements to locate a hidden object. In fact, by age 5 , children strongly favored the location that was associated with the stronger modal (i.e., must). A number of studies have demonstrated similar findings with other modal pairs (Byrnes and Duff 1989; Noveck et al. 1996), and similar results were reported for the contrast between the modals potere/dovere in Italian (Bascelli and Barbieri 2002). Taken together, these findings provide compelling evidence that, by age 5 , children are sensitive to the quantificational force conveyed by different modals. Although an explanation of Moscati's results in terms of lexical misinterpretation does not seem viable, there were other limitations to the study that potentially blunt the force of any conclusions that can be drawn. First, there were no suitable controls to ensure that children were paying attention to the QUD. If children were ignoring the QUD, this alone could explain why Moscati found no effect across conditions. Second, the study did not include nominal quantifiers, precluding a direct comparison between children's responses to modals and to nominal quantifiers. We are left with only indirect comparisons, based on different experimental materials and different tasks. The goal of the present study was to overcome these possible limitations, in order to see whether children's interpretations of negative sentences with modals constitute a serious challenge to the QAR account. ${ }^{6}$

\section{Experiment 1}

A Truth Value Judgement Task (TVJT) was conducted to investigate whether adherence to the QAR grants children access to the problematic readings for negative sentences with either nominal quantifiers or with modals (Crain and Thornton 1988).

\footnotetext{
4 Thanks to an anonymous reviewer for pointing this out to us.

5 In addition, one would have to assume that children are unable to access the inverse scope of (11), which, by contrast, would be compatible with the context (assuming può is misanalysed as deve).

6 An anonymous reviewer offered another potential issue to be considered here. The observation is that negation is adjacent to the modal in all of the test sentences: to its right in the sentences that generate the strong reading non > può, and to its left in sentences that generate the weaker alternative può $>$ non. The adjacency of the two operators might lead to parsing errors, inducing children to treat the sequence mod $>n e g$ as the more canonical neg $>$ mod. To control for this, one could look at languages where negation resides in an adverbial particle that does not require a verbal host (e.g., German). This is an important issue to investigate in future research.
} 
There were two experimenters. One acted out short vignettes using toy characters and props, and the second experimenter played the role of a puppet who watched the stories alongside the child. At the end of each story, the outcome was made explicit by the arrangement of the characters. Following each story, the puppet was asked two questions. One question established the QUD. Following the puppet's answer to the QUD, the puppet was asked a second question. This was a wh-control question (e.g., Who gave the carrots to the elephants?), and was included to assess whether the child subject was paying attention to the experimenter's QUDs. The child's task was to judge whether or not the puppet's answers to both questions accurately described what had happened in the story.

\subsection{Methods}

\subsubsection{Participants}

Sixteen monolingual Italian-speaking children (mean age 5;6, range 4;10-5;8) participated in Experiment 1, and 10 adults were tested as controls.

\subsubsection{Materials and procedure}

Each participant was presented with ten stories. Following each story, the participant was required to give two responses. First the experimenter asked the puppet a yes/noquestion. The puppet responded with a complete sentence, and the participant was then instructed to indicate whether the puppet's response was correct. Second, the experimenter asked the puppet a wh-question. In response, the puppet produced a fragment answer (a DP), and the participant was instructed again to indicate whether the puppet's response was correct. For three of the stories, the experimenter's yes/no-question included both negation and an existentially quantified DP. The puppet's responses to these yes/no-questions were always true, from the adult perspective. The experimenter's wh-question also included negation and an existentially quantified DP. In all the three wh-questions, the puppet's response to the wh-question was false, from the adult's perspective. Here is an example of a nominal quantifier trial (we report all target stories in Appendix B):

Quantifier story:

"Jack, the photographer, and Fred, the caveman, are going to take photos of animals in the jungle. Two crocodiles and two elephants are walking by. Jack and Fred decide to try to take pictures of them. Fred tries first, however he doesn't manage to shoot any of them. Then it is Jack's turn. He manages to take photos of the elephants, but not of the crocodiles."

At this point, the experimenter asked the puppet the question in (15) and the puppet answered as in (16).

(15) QUD: Il fotografo ha fotografato tutti gli animali?

$\{\forall, \neg \forall\}$

'Did the photographer shoot all of the animals?' 
(16) Il fotografo non ha fotografato qualche animale.

the photographer not has shot some animal

a. There are some animals the photographer didn't shoot $\quad(\exists>\neg)$

b. The photographer didn't shoot any animal

It is easy to verify that both interpretations of (16) are correct answers to the QUD, because both entail the negative member of the question. Moreover, (16) is true in the context given in (14) only if it is interpreted as in (16a).

After the yes/no-question the puppet asked a wh-question, as in (17). Notice that children cannot successfully judge the accuracy of the puppet's answer in (17b) unless they relate it to the wh-question. ${ }^{7}$
a. Chi non ha fotografato nessun animale?
'Who didn't shoot any animal?'
b. Il fotografo.
'The photographer.'

Finally, the test session included two other stories in which the experimenter asked a yes/no-question, but where the puppet responded with a sentence that contained an existential quantifier without negation. These answers were false descriptions of the context, from an adult's perspective. In addition, the experiment asked a wh-question to which the puppet responded with a fragment answer that was true from an adult's perspective. These additional trials were included to control for the number of positive sentences without negation, and to balance the number of true and false sentences. In sum, there were three target sentences involving negation and an existential quantifier for the nominal quantifier condition, plus three false wh-controls, two true wh-controls, and two positive sentence controls.

The modal condition included the same complement of test sentences and controls. There were three stories where the puppet responded first to a yes/no-question that contained a sentence involving the existential modal può and negation, and then to a control wh-question with a fragment answer. Again, from an adult's perspective, the puppet's responses to the yes/no-questions were always true while the puppet's responses to the wh-controls were always false. A typical trial is given in (18).

\section{Modal story:}

"Fred and Smurfette went to visit Papa Smurf at his faraway home. He lives very far away and they need to take a motorbike to get there. A motorbike is there for them to use. Smurfette says that the bike is too dangerous and, besides, she doesn't know how to drive it. Only Fred is tall enough to drive it. Fred is considering using it, but in the meanwhile a pilot comes and he offers Fred his car. Now Fred has two choices: he can take the bike or the car."

\footnotetext{
${ }^{7}$ And arguably reconstruct a full representation on the basis of the antecedent, along the lines of (i); see Merchant 2001, among others.
}

(i) Il fotografo $<$ non ha fotografato nessun animale $>$ 
At the end of the story, Fred was free to choose between the car and the bike. In other words, he could take the bike but didn't have to. At this point, the experimenter posed the question in (19) to the puppet, and it replied with (20).

(19) QUD: Fred deve guidare la moto?

'Must Fred drive the bike?'

(20) Fred può non guidare la moto.

Fred MOD not drive the bike

a. It is possible for Fred not to drive the bike

$(\diamond>\neg)$ (TRUE)

b. *It is not possible for Fred to drive the bike

$(\neg>\diamond)($ FALSE)

Again, both of the interpretations of (20) are good answers to the QUD, as both entail the negative member in (19). Moreover, the target sentence was true, under the interpretation in (20a). Analogously, the modal stories were followed by a whquestion, which corresponded to a negative sentence. For example, in the context of the story in (18), the puppet was also asked the question below in (21).
a. Chi non può guidare la moto?
'Who cannot drive the motorbike?'
b. Puffetta.
'Smurfette.'

As before, there were two additional stories involving può without negation and a true wh-control. In sum, the modal condition introduced three target sentences, three false wh-controls, two true wh-controls, and two positive sentences controls.

Importantly, the true readings in the context are good answers to the explicit QUD in both the nominal quantifier and the modal conditions. The QAR account therefore predicts that children should accept the target sentence to the same extent in both conditions.

\subsection{Results and discussion}

Figure 1 summarizes the proportion of correct answers for the fragment answers and the proportion of correct rejections for the positive controls.

As the figure illustrates, children's performance in response to the control items was similar to that of adults. Children correctly rejected the positive control statements at a rate above $80 \%$ for both modals and nominal quantifiers. Children also experienced little difficulty accepting and rejecting the puppet's fragment answers. Their proportion of correct answers remained at above $80 \%$. These findings suggest that children were paying attention to the questions posed by the puppet and judged the puppet's fragments as they pertained to the QUD. We turn next to data from the two experimental conditions, which are summarized in Fig. 2.

As Fig. 2 shows, children accepted the test sentences with existential quantifiers $\approx 90 \%$ of the time. This was only slightly lower than the adult rate of $\approx 97 \%$. By contrast, children's acceptance rate for negative sentences with modals dropped to $\approx 44 \%$, whereas adults remained at $\approx 97 \%$. 

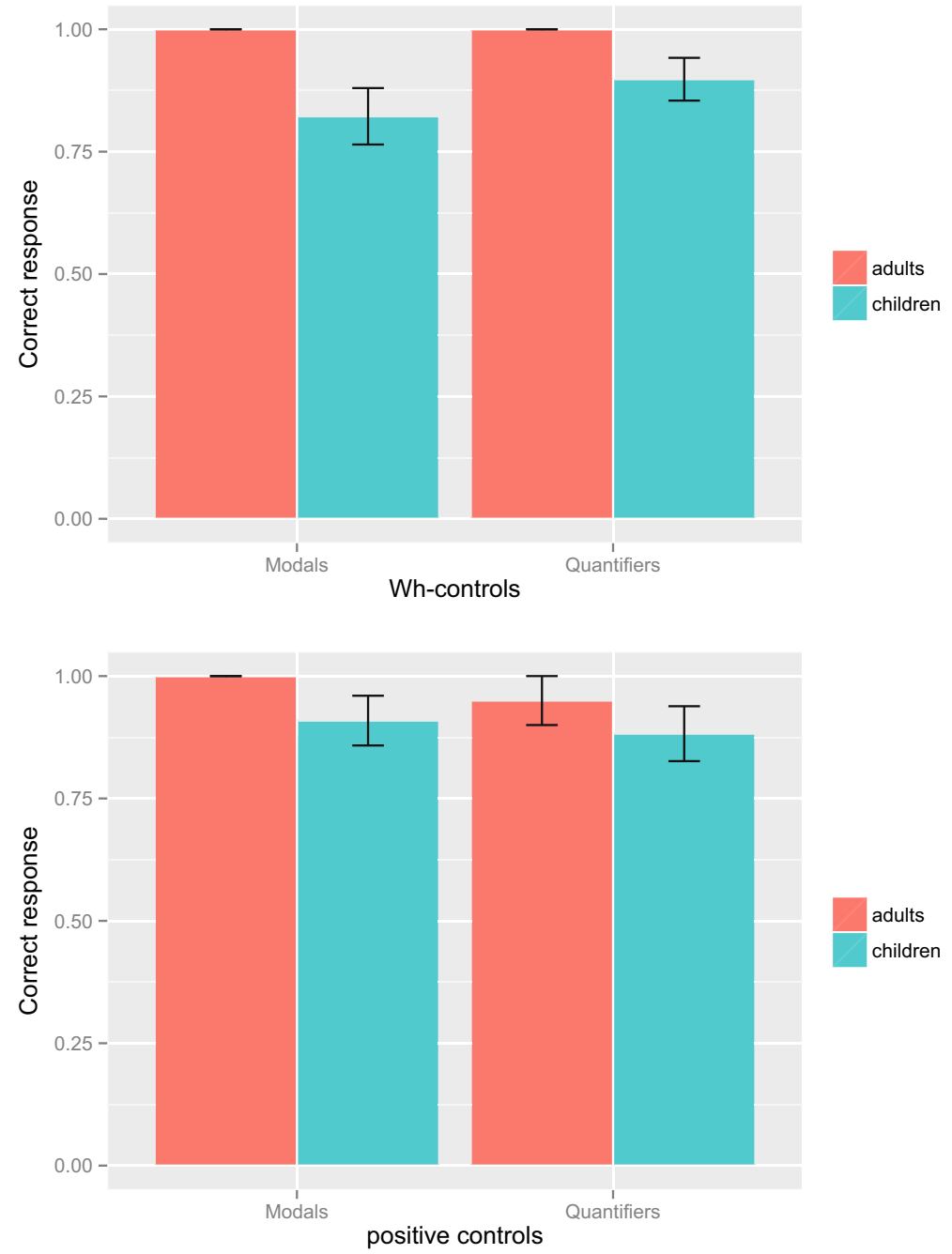

Fig. 1 Proportion of correct truth value judgements of wh-control and positive controls

Looking more closely at children's responses in the modal condition, we found that the majority of children consistently behaved differently from adults: rejecting the target sentences either all of the time ( 5 children out of 16) or two times out of three ( 6 children). In addition, there was a group of 3 children who consistently behaved in the same way as adults and another 2 children who accepted two of the three target sentences. ${ }^{8}$ Following previous studies in the literature, we assume these

\footnotetext{
8 Eight of the child participants produced one answer that differed from the other two. This could simply be a reflection of the higher variability in the child data (see Appendix A). Another possibility is that these children were going through a transitional stage of language development at which they were temporarily drawing upon two grammars.
} 


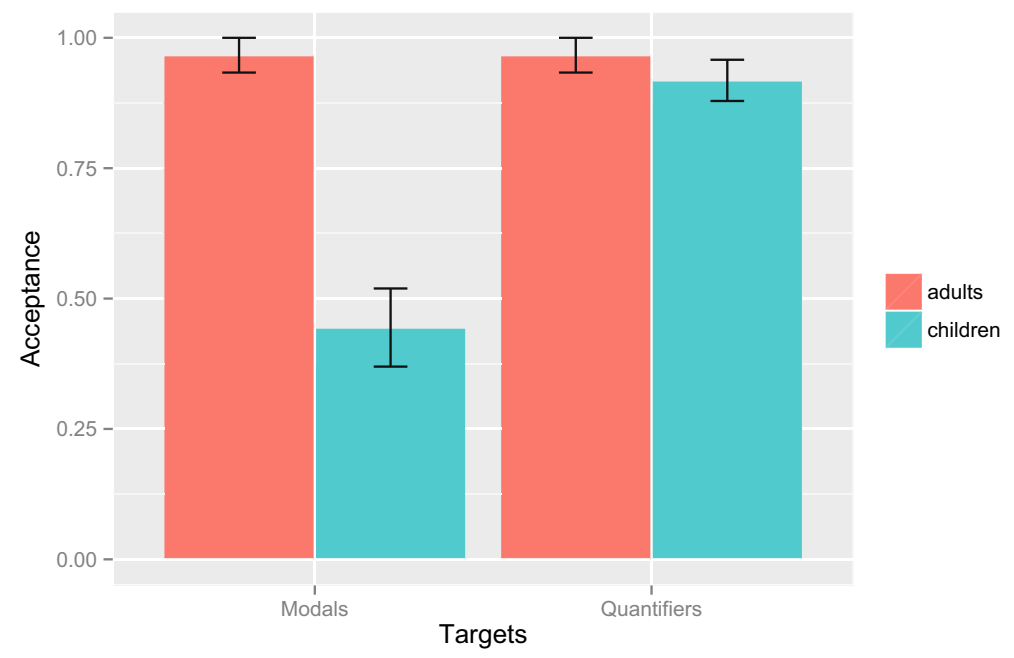

Fig. 2 Proportion of correct truth value judgments of target items

children in these two latter groups are effectively adults in their relevant linguistic knowledge. ${ }^{9,10}$

Data were analysed in $\mathrm{R}$ using generalized linear mixed-effects models, with Operator-Type as predictor, or fixed effect, and Participants and Items as random effects (Baayen 2008). The analysis revealed a main effect of the Operator-Type $(\mathrm{p}<.001)$ : children experienced modal-type questions as significantly more difficult to gauge than their quantifier-type counterparts. Results of the analysis and additional comments are provided in Appendix A.

The present experiment manipulated QUDs for two types of logical operators: modals and nominal quantifiers. One main finding replicated the result of Gualmini et al. (2008). Both studies found that children are able to access the true reading of negative sentences with nominal quantifiers, as long as this reading answers the explicit QUD in the context. However, we also replicated the finding by Moscati (2011). In both his and our study, children were unable to access the true reading of negative sentences with modals, even when this reading felicitously answered the explicit QUD in the context. Modals appear indeed to constitute a challenge for the QAR model.

Our study was designed to overcome the possible limitations of the study by Moscati (2011), in two ways. One feature of the present study was to investigate negative sentences with modals and ones with nominal quantifiers using the same child participants. Children's responses to sentences with nominal quantifiers were consistent with the

\footnotetext{
9 One of the children in this last group actually did not provide an answer for the third modal story, so her pattern of response is actually that two responses out of two were adult-like.

10 We report on each story individually in Appendix B. As far as modals are concerned, all the target stories yielded an acceptance rate that was lower than the adult one. Among them, target story 5 was the one presenting the lowest acceptance rate, attested at $31 \%$ in children. The acceptance rates of target stories 6 and 4 were 46 and $57 \%$ respectively. To take into account this variability, the stories are treated as random effects in the statistical analysis of the data in Appendix 1.
} 
QAR, but their responses to sentences with modals were not. In view of the effect of the QUD in guiding children's responses to sentences with nominal quantifiers, there is no reason to believe that our child participants were selectively ignoring the QUD in modal sentences. Moreover, the fact that the children correctly responded to the control sentences demonstrates that they attended to the question under discussion. But if children were not ignoring the QUD, then the present results effectively challenge the proposal by Gualmini et al. (2008).

One question at this point, however, is whether children's difficulty with modals lies in realizing that the target sentences are in fact answers to the given QUDs-in other words, whether they might find it hard to realize that, say, (22) is a good answer to (23). In particular, one thing that might play a role is that the modal is not the same in the question and the answer (deve vs. può).

Fred deve guidare la moto?

Fred must drive the bike?

Fred può non guidare la moto.

Fred MOD not drive the bike

In order to consider sentence (23) a good answer to (22), children have to realize that può non is logically equivalent to non deve. Although these two expressions have the same meanings, they make use of different lexical items: a universal modal in the question and an existential modal in the answer. We can speculate that this idiosyncrasy might be a source of confusion for children. Notice that this hypothesis leaves open why they should have a problem with modals in this respect but not with nominal quantifiers, given in particular that there is a corresponding difference between the nominal quantifier in the question and that in the answer (tutti vs. qualche). Let's assume, however, that there might be some asymmetry in understanding that (23) is an answer to (22) versus understanding that (25) is an answer to (24).

Il fotografo ha fotografato tutti gli animali? The photographer has shot all the animals?

(25) Il fotografo non ha fotografato qualche animale.

The photographer not has shot some animal

If the use of a different modal in the question-answer pair does indeed add some complexity to the task, then we should be able to get rid of this factor by using the same operator both in the question and in its answer. Under the working hypothesis that similarities in the logical forms of the question and the answer could facilitate the task, we can test the effect of the QUD by changing it in such a way that it will share the same lexical material with the target answer.

We think this hypothesis is worth pursuing because (the three of us who are) native speakers of Italian find that (23) is more easily recognized as an answer to (26) than to (22). Notice that (26) has the same modal as the answer in (23). One might ask whether this intuitive difficulty in relating (22) and (23) could have played a role in children's responses in our Experiment 1. 
(26) Fred può non guidare la moto?

Fred MOD not drive the bike?

Experiment 2 explores this hypothesis. It is a replication of Experiment 1, except that we changed the QUD from (22) to (26) and correspondingly from (24) to (27).

Il fotografo non ha fotografato qualche animale?
The photographer not has shot some animal?

\section{Experiment 2}

\subsection{Method}

\subsubsection{Participants}

In this experiment, 32 monolingual Italian-speaking children (mean age $=5 ; 3$, range $=4 ; 10-5 ; 9)$ and 22 monolingual Italian-speaking adults took part. Children were randomly assigned to two different groups: one group $(\mathrm{G} 1: \mathrm{N}=16)$ heard the sentences with modals, while the other heard sentences with quantifiers $(\mathrm{G} 2: \mathrm{N}=16)$. Both groups had a series of filler stories interspersed between the target trials.

\subsubsection{Materials and procedure}

Materials were the same as used in Experiment 1. However, unlike in Experiment 1, the variable operator (Nominal quantifier vs. Modal) was manipulated between subjects. We used a between-subject design, because we had the impression during pilot testing that some children found Experiment 1 to be too long. By dividing children into two groups, we shortened the experiment. Children assigned to the modal group heard three target stories in which the target sentence was presented after an explicit QUD. In each trial, the puppet also had to answer to a control wh-question. In addition, as in Experiment 1, interspersed between the three target stories there were two positive controls; these were false descriptions of the corresponding scenarios. Children assigned to the quantifier condition also heard three target stories-exactly the same ones used in Experiment 1-plus two fillers and two wh-questions. The only difference was in the form of the QUD. Consider again the quantifier story in (28), repeated from above.

Quantifier story:

"Jack, the photographer, and Fred, the caveman, are going to take photos of animals in the jungle. Two crocodiles and two elephants are walking by. Jack and Fred decide to try to take pictures of them. Fred tries first, however he doesn't manage to shoot any of them. Then it is Jack's turn. He manages to take photos of the elephants, but not of the crocodiles."

Now, at the end of this story, instead of the question in (29), children heard the question in (30). 
(29) QUD: Il fotografo ha fotografato tutti gli animali?

'Did the photographer shoot all of the animals?'

$\{\forall, \neg \forall\}$

(30) QUD: C'è qualche animale che non è stato fotografato dal fotografo?

'Is there any animal that wasn't shot by the photographer?'

$\{\exists \neg, \neg \exists \neg\}$

At this point, the puppet gave exactly the same answer as in Experiment 1.

(31) Il fotografo non ha fotografato qualche animale.

The photographer not has shot some animal

a. There are some animals the photographer didn't shoot $\quad(\exists>\neg)$ TRUE

b. The photographer didn't shoot any animal $\quad(\neg>\exists)$ FALSE

Notice that now the nominal quantifier is the same in the QUD and in the answer. The same logic was used also for modal sentences. Again, consider the following modal story, repeated from above.

\section{Modal story}

"Fred and Smurfette went to visit Papa Smurf at his faraway home. He lives very far away and they need to take a motorbike to get there. A motorbike is there for them to use. Smurfette says that the bike is too dangerous and, besides, she doesn't know how to drive it. Only Fred is tall enough to drive it. Fred is considering using it, but in the meanwhile a pilot comes and he offers Fred his car. Now Fred has two choices: he can take the bike or the car."

As in Experiment 1, Fred was free to choose between the car and the bike. Now the experimenter asked the question in (34), rather than that in (33).

QUD: Fred deve guidare la moto?

'Must Fred drive the bike?'

$\{\square, \neg \square\}$

QUD: Fred può non guidare la moto?

'Can Fred not drive the bike?'

$\{\diamond \neg, \neg \diamond \neg(=\square)\}$

And the puppet replied using the same sentence as in Experiment 1.

(35) Fred può non guidare la moto.

Fred MOD not drive the bike

a. It is possible for Fred not to drive the bike

$(\diamond>\neg)$ (TRUE)

b. *It is not possible for Fred to drive the bike

$(\neg>\diamond)($ FALSE)

Again, if using the same modal in both the question and the answer has a facilitating effect, we would expect children's performance with quantifiers and modals to improve in Experiment 2. 

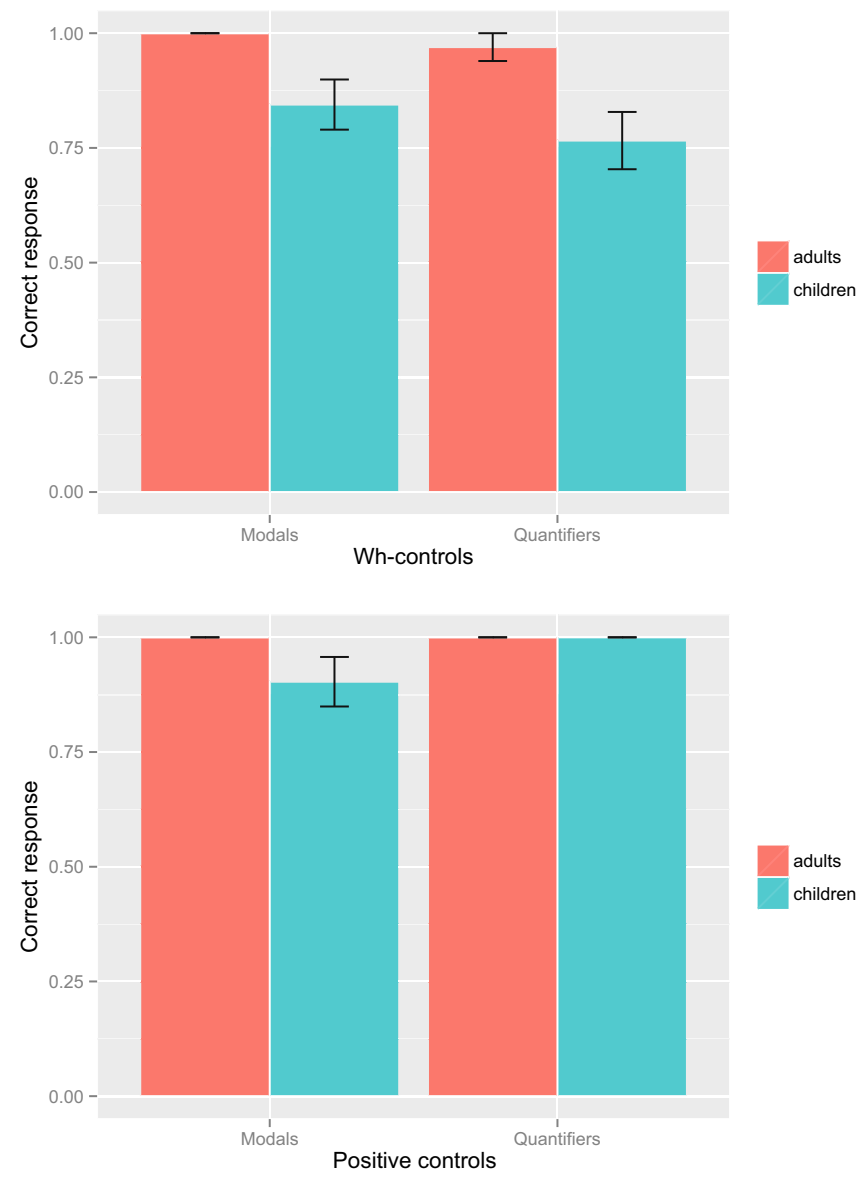

Fig. 3 Proportion of correct truth value judgements of wh- and positive control items

\subsection{Results and discussion}

Figure 3 report's children's answers to the wh-controls for both the quantifier and the modal stories, as well their rate of correct answers to the filler stories. Figure 4 reports instead children's acceptance rate in the target stories. Notice that in both conditions, the observed proportions are almost the same as in Experiment 1. Again, the majority of children in the modal condition consistently produced different responses than adults did, with 11 out of 16 children rejecting at least two of the three target sentences. ${ }^{11}$

\footnotetext{
11 The three modal stories in Experiment 2 were accepted by children 35, 31 and $53 \%$ of the time (see Appendix 2). Analogously to Experiment 1, in the statistical analysis we model the stories as random effects. This accounts for the difference in acceptance rate. It would be conceivable that certain fine-grained distinctions among root modalities could have played a role in determining these numerically different rates of acceptance. That is, differences in the story contexts could have favoured different modal base interpretations which, in turn, could have made one reading more salient than another. Nonetheless, from the results presented in Appendix 1, it is clear that the main effect of modality overall cannot be reduced to
} 


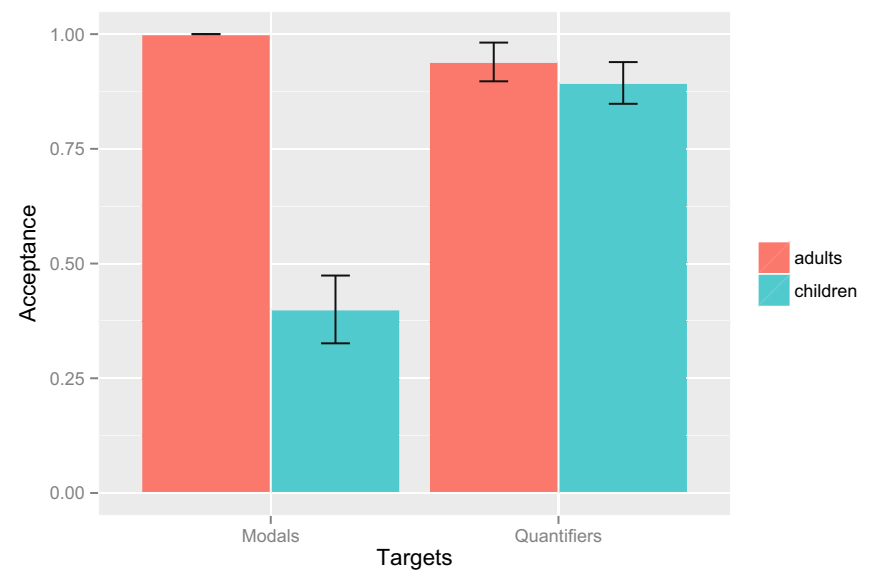

Fig. 4 Proportion of acceptance of target items

As in Experiment 1, the data were analysed in $\mathrm{R}$ using generalized linear mixedeffects models, with Operator-Type as predictor and Participants and Items as random effects. Again, the analysis revealed a main effect of the Operator-Type on children. Results of the analysis are summarized in Appendix 1.

In sum, we found no effect of the question type on modals. We found the same effect as in Experiment 1 on nominal quantifiers. In other words, despite the question and answer containing the same modal and despite the intuition that this facilitates understanding the question-answer relation, children appeared unable to access the adult's reading in the modal case, in the same way as in Experiment 1.

\section{General discussion}

Experiment 1 confirmed that adherence to the QUD makes the adult readings of negative sentences with nominal quantifiers available to children, as proposed in Gualmini et al. (2008). However, this did not prove to be the case for negative sentences with existential modals. For adults, existential modals must be interpreted outside the scope of negation. In contrast to adults, children failed to access the weak, surface scope reading, in both Experiment 1 and Experiment 2. Instead, children continued to assign the non-adult inverse scope reading in both experiments, just as they had in previous studies (Moscati 2011, 2013; Moscati and Crain 2014). Experiment 1 compared the two operators in the same experiment; it also introduced a control to ensure that children were paying attention to the question under discussion. Experiment 2 further modified the QUDs so that they contained the same modal/nominal quantifier both in the question under discussion and in the answer. The intuition was that this might facilitate

Footnote 11 continued

item-variability. Note, moreover, that while the child participants accepted one test sentence at a relatively high $53 \%$, this figure is much lower than the acceptance rates for the test sentences that contained nominal quantifiers. 
children's understanding that the target sentence is an answer to the QUD and that this, in turn, might improve children's performance in the modal condition. However, we found no effect of this modification of the QUD, despite extensive experimental maneuvers to support children's access to the adult surface scope reading of the modal sentences.

Taken together, the results of Experiment 1 and 2 suggest that the weak readings of negative sentences with existential modals are simply not available to children at this developmental stage. This poses a challenge to the QAR model. It appears indeed that, at least in the case of modal sentences, all Italian-speaking children go through a Unique Scope Assignment stage (the USA stage). In the following, we briefly sketch our proposed modification to the model of acquisition that underlies the QAR account.

As we saw, the QAR model as originally conceived is a two-stage model of acquisition. At the first stage, the QAR is more highly ranked than the Principle of Charity. At this stage, children are expected to reject ambiguous sentences if no reading is both true and felicitous in the context-with a sentence being considered felicitous if it a good answer to the salient QUD. Moreover, children are expected to reject ambiguous sentences when they have readings that are true, but not felicitous, in the context. At the first stage, then, the QAR outranks the Principle of Charity. At the second stage, older children/adults rank the Principle of Charity more highly than the QAR — which is to say, more highly than discourse congruence. At this stage, if an ambiguous sentence has a reading that is true in the context, children/adults will accept it, even if this requires accommodating a new QUD. The model is schematically represented in (36).

$$
\begin{aligned}
& \text { Two-stage model } \\
& \text { Stage 1: QAR > Charity } \\
& \text { Stage 2: Charity > QAR }
\end{aligned}
$$

It is clear that the model in (36) cannot account for the asymmetry we observed in children's responses to negative sentences with modals, as compared to negative sentences with numeral quantifiers. We therefore now propose a modification of the two-stage model, which includes an initial stage at which children have access to only one interpretation of potential scope ambiguities. The revised model is summarized in (37).

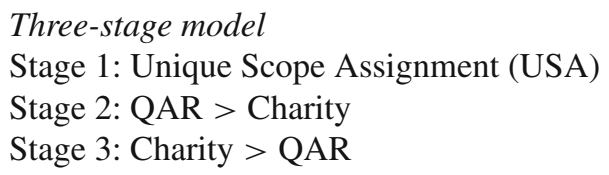

Three-stage model

Stage 1: Unique Scope Assignment (USA)

Stage 2: QAR > Charity

Stage 3: Charity $>$ QAR

A question at this point is how general the model in (37) should be interpreted to be. We have only presented evidence for a USA stage in the acquisition of negative sentences with existential modals. Therefore, the present findings only support a narrow interpretation of (37), restricted to the difference between sentences with modals versus ones with nominal quantifiers. One could, however, interpret the model in (37) more generally, as applying across different modals and across different operators. The finding that children make the transition from the first stage to the second stage at different 
rates, depending on the operator involved, could also be accounted for on this general interpretation of the model. For instance, if some particular operator is acquired later than another operator in child grammar, we would expect to find children making a later transition from the first stage to the second stage for that particular operator. It has been suggested in the literature that modals are acquired later than nominal quantifiers (Noveck 2001, among others). This would explain why 5-year-old children appear to be at the Unique Scope Assignment stage in responding to negative sentences with modals, but not to ones with nominal quantifiers. This general interpretation of the model in (37) also predicts that children will be found to go through a USA stage with nominal quantifiers at an earlier period of development.

In sum, while pragmatics plays a crucial role in the interpretation of ambiguous sentences by both children and adults, the findings of the present experiments support the existence of a stage in language development at which children access only a subset of the interpretations available to adults, at least for ambiguous sentences involving existential modals and negation. We must leave open for now the question of whether this unique assignment stage extends beyond the case of modal sentences. Nevertheless, the existence of a stage in development at which children access only one of the possible adult readings raises the question of how to account for children's initial assignments. A definitive answer to this question is beyond the scope of this paper. Notice, however, that among the alternatives laid out in Sect. 1 above, the findings from the present study argue against an account of initial scope assignments that is based on an isomorphic mapping between surface order and interpretation. Such an account cannot, on the face of it, explain children's initial assignment of scope relations in negative sentences with existential modals. As we have seen, children's initial scope assignment for such sentences is the non-isomorphic reading. For example, children interpret sentence (38) as (38b) and not as (38a).

Fred può non guidare la moto.

Fred MOD not drive the bike

a. Fred might not drive the bike

b. *Fred cannot drive the bike

One generalization across all the cases we have considered is that children appear to start with the stronger of the two possible readings of the ambiguous sentences in question. This is compatible with a learnability-based approach according to which children always initially assign the strongest possible scope configuration for ambiguous sentences (see Moscati and Crain 2014 for discussion of how this approach applies to modal constructions).

One other question remains, in addition to the question of why children initially prefer the inverse scope readings of the modal sentences. The remaining question is how this reading is expunged from children's grammar. ${ }^{12}$ In other words, what blocks the inverse scope reading of negation over the modal in the adult grammar? A possible explanation of this capitalises on the observation that inverse scope phenomena of the sort discussed in the present paper are clause bounded. It has been noticed since

12 Thanks to an anonymous reviewer for discussion on this point. 
Rizzi (1982) that sentential negation in modal sentences forces the introduction of a clause boundary. The resulting bi-clausal structure accounts for a range of different syntactic phenomena. Therefore, a sentence like (39) has the representation in (40), in which the modal takes a sentential complement.

Fred può non guidare la moto.

This bi-clausal structure may explain why negation cannot take scope over the modal in cases like (39). ${ }^{13}$ If so, we should expect that as soon as children become aware of the structure in (40) on the basis of various syntactic evidence (see Cardinaletti and Shlonsky 2004 for a discussion of the properties of these constructions), they would be expected to disallow the inverse scope reading of negation over other operators in the main clause. Notice that this explanation is parallel to the one generally given to the same question with respect to existential quantifier sentences like (41), repeated below. In the latter case, children would lose the surface scope interpretation, which is unavailable in adult grammar for most speakers, as soon they would learn that some is a positive polarity item (PPI) and cannot appear in the immediate scope of negation. In both cases, therefore, an additional element (i.e., bi-clausality and PPIness, respectively) comes into play later in acquisition, thereby allowing children to converge on the adult grammar.

(41) The detective didn't find some guys.

Before closing, let us note one new direction that emerges from the modification of the QUDs in Experiment 2. Recall that in that experiment we used questions like (42) and (43). Notice that these questions themselves contained a negation and a nominal quantifier/modal. This invites us to ask what scope assignments children make in analyzing such questions. For example, one possible interpretation of the question in (43) asks whether it is possible for Fred not to drive the bike $(\diamond>\neg)$; another possible interpretation asks whether it's impossible for Fred to drive the bike $(\neg>\diamond)$.

(42) C'è qualche animale che non è stato fotografato dal fotografo?

'Is there any animal that wasn't shot by the photographer?'

Fred può non guidare la moto?

'Can Fred not drive the bike?'

\footnotetext{
13 The clause boundary in (40) is witnessed by a series of blocking effects, among them the well-known impossibility to have clitic climbing. Without negation, either proclisis on the higher modal (i-a) or enclisis on the lower lexical verb (i-b) are possible. However, when the modal takes a clausal complement in negative sentences, the clitic cannot appear on the higher clause (ii-a) and only enclisis on the verb in the lower clause is allowed (ii-b).
}

(i) a. Fred la può guidare.

b. Fred può guidarla.

(ii) a. *Fred la può [ $C P$ non guidare $]$

b. Fred può [ $C P$ non guidarla $]$ 
The QAR is silent on the topic of how children interpret questions. Presumably there is no QUD that guides the interpretation of a QUD itself. An account of ambiguity resolution compelling children to start with the strongest reading is also silent on this topic. The account based on information strength is silent too, because the two possible interpretations of questions like (43) do not stand in an asymmetric entailment relation. More precisely, the yes-answer of (45) entails the yes-answer of (44), but of course it is the other way round for the no-answers: the no-answer to (44) entails that of (45). At least prima facie it is not clear that there is a 'strongest' interpretation for questions like (43).

$$
\begin{aligned}
& \left\{\begin{array}{l}
\lambda w \llbracket\left[\text { Fred può non guidare } \rrbracket^{w},\right. \\
\lambda w\left(\neg \llbracket \text { Fred può non guidare } \rrbracket^{w}\right)
\end{array}\right\}=\{\diamond \neg, \neg \diamond \neg(=\square)\} \\
& \left\{\begin{array}{l}
\lambda w \llbracket \text { non[Fred può guidare }] \rrbracket^{w}, \\
\left.\lambda w(\neg \llbracket \text { [non[Fred può guidare }] \rrbracket^{w}\right)
\end{array}\right\}=\{\neg \diamond, \neg \neg \diamond(=\diamond)\}
\end{aligned}
$$

To conclude, investigating how children interpret scopally ambiguous questions such as those we used in Experiment 2 represents a novel direction for research in this area. We must leave the exploration of this domain for future work.

Acknowledgments For helpful discussion and suggestions, we would like to thank Cory Bill, Lyn Tieu, Richard Williams, two anonymous reviewers, and the audiences at GALA 2013 and Xprag 2013 Utrecht. We also thanks the teachers, parents, and children from the kindergarten 'Mameli' in Florence and from 'San Benedetto' in Siena. This work was supported by the Australian Research Council Centre of Excellence for Cognition and its Disorders (www.ccd.edu.au) under grant CE110001021 and by the Singapore National Research Foundation under NRF Award NRF-NRFF2013-01. For the purpose of the Italian academic system, V. Moscati, J. Romoli, and S. Crain equally contributed to Sects. 1-5. T. Demarie contributed to the data analysis and to the discussion in Appendix 1.

Open Access This article is distributed under the terms of the Creative Commons Attribution 4.0 International License (http://creativecommons.org/licenses/by/4.0/), which permits unrestricted use, distribution, and reproduction in any medium, provided you give appropriate credit to the original author(s) and the source, provide a link to the Creative Commons license, and indicate if changes were made.

\section{Appendix 1: Statistical analysis of the data}

In this appendix we present the statistical analysis of the data sets used in the experiments described in the main text. Recall that in this work we deal solely with outcome variables in the form of categorical data: each subject under examination can either provide a wrong (0) or a correct (1) answer (or rejection) to a trial.

As explained in Jaeger (2008), the most natural method to treat categorical outcome variables is by using a linear logistic regression. For such a model, the natural logarithm of the odds of an event (with probability $p$ ) is linearly related to the $n$ independent variables (or covariates) $x_{i}$,

$$
y=\ln \frac{1-p}{p}=\beta_{0}+\sum_{i}^{n} x_{i} \beta_{i}+\epsilon
$$


with $\beta_{0}$ intercept, $\beta_{i}$ regression parameters, and a random error $\epsilon$. Note that there is a non-linear relationship between the probability $p$ and the linear predictor $y$, which is realised by the so-called logit function. The value of $p$ can easily be extracted by inverting the first part of the equation above, namely:

$$
p=\frac{1}{1+e^{-y}} .
$$

In the experiments, there could be four possible covariates: The variables Operator, Group, Subject, and Item. It is important to note that conditional independence of the data is violated whenever we are collecting observations from the same subject. Furthermore, multiple investigations of the same item introduce random effects that a simple linear regression fails to take into account. To account for these influences, we model the variables Subject and Item as random effects using mixed logistic models; these belong to the broader class of Generalised Linear Mixed Models (Breslow and Clayton 1993), which also includes the most widely known linear mixed-effects model (see Baayen et al. 2008 for applications to linguistic materials). Under these assumptions Eq. (1) becomes: ${ }^{14}$

$$
y=\ln \frac{1-p}{p}=\beta_{0}+\sum_{i}^{n} x_{i} \beta_{i}+\sum_{j}^{m} z_{j} B_{j}+\epsilon
$$

with $m$ covariates $z_{j}$ associated to the random effects $B_{j}$ (note that $B_{j} \sim N\left(0, \sigma_{j}^{2}\right.$ ) for some variance $\sigma_{j}^{2}$ ).

In our experiments, $p$ is the expected outcome of the sentence under examination, within the limits of 1 for a correct outcome and 0 for a wrong one. If we were to treat the data collectively, as a single set, the form of Eq. (3) would be:

$$
\ln \frac{1-p_{s, i}}{p_{s, i}}=\beta_{0}+g \beta_{1}+o \beta_{2}+B_{s}+B_{i}+\epsilon_{s, i},
$$

where $g=0,1$ is the group variable (children or adults), $o=0,1$ is the Operator variable (quantifiers or modals), $B_{s} \sim N\left(0, \sigma_{s}^{2}\right)$ and $B_{i} \sim N\left(0, \sigma_{i}^{2}\right)$ are the Subject and Item random effects respectively, and $\epsilon_{s, i} \sim N\left(0, \sigma^{2}\right)$ is the random error.

Although this procedure seems sound, it still entails a risk. In the underlying framework of logistic regression, the variance is assumed to be equal for all covariates. However, this assumption is violated if the variance of one of the independent variables increases or decreases, a condition known as heteroscedasticity. Heteroscedasticity can produce biased and misleading parameter estimates, as was pointed out by Allison (1999) first, and recently reviewed in Mood (2010).

Qualitatively, if one observes the distribution of wrong and correct answers (the 0s and 1s) for children and adults (see Table 1 below), the two groups appear to be heterogeneous, which is a qualitative hint of heteroscedasticity.

If such behavioural difference exists, the relationship among variables might not be the same for the dependent variables associated to the two groups, and a single linear regression for the entire range of answers would not be appropriate. Hence, for

14 From now on, we avoid to write the $y$ symbol in the equations. 
Table 1 Distribution of 0 s and $1 \mathrm{~s}$ in the experimental outcomes

\begin{tabular}{|c|c|c|c|c|}
\hline & \multicolumn{2}{|l|}{ Experiment 1} & \multicolumn{2}{|l|}{ Experiment 2} \\
\hline & Target QUD & Control wh-questlon & Target QUD & Control wh-question \\
\hline \multicolumn{5}{|c|}{ Children } \\
\hline 1 & 61 & 76 & 60 & 74 \\
\hline 0 & 28 & 13 & 32 & 18 \\
\hline \multicolumn{5}{|c|}{ Adults } \\
\hline 1 & 58 & 60 & 64 & 65 \\
\hline 0 & 2 & 0 & 2 & 1 \\
\hline
\end{tabular}

Table 2 Results of the Breusch-Pagan test for heteroscedasticity

\begin{tabular}{llllll}
\hline & \multicolumn{4}{l}{ Breusch-Pagan Test for heteroscedasticity } \\
\cline { 2 - 3 } & \multicolumn{2}{l}{ Experiment 1 } & & Experiment 2 & \\
\cline { 2 - 3 } \cline { 5 - 6 } & $\mathrm{BP} \chi^{2}$ & $\mathrm{p}$ value & & $\mathrm{BP} \chi^{2}$ & $\mathrm{p}$ value \\
\hline Target QUD & $1.238 \mathrm{e}^{+1}$ & $0.205 \mathrm{e}^{-2}$ & & $1.112 \mathrm{e}^{+1}$ & $0.384 \mathrm{e}^{-2}$ \\
Control wh-question & $7.318 \mathrm{e}^{+1}$ & $\ll \mathrm{e}^{-5}$ & & $5.842 \mathrm{e}^{+1}$ & $\ll \mathrm{e}^{-5}$ \\
\hline
\end{tabular}

additional evidence of heteroscedasticity, we perform a Breusch-Pagan test on the data to check for different residual behaviour between the children's and adults' data. We test the data from Experiment 1 and Experiment 2, looking at the linear relationship $y_{s, i}($ answer $) \sim$ operator + group, where the variable Group can take the value of children or adults, and the variable Answer represents either the target QUDs or the control wh- questions. The results of the Breusch-Pagan test, shown in Table 2 below, indicate presence of heteroscedasticity across the data for both experiments. In fact, a large value of the $\chi$-square and a small $p$-value tell us that homoscedasticity cannot be assumed; see Breusch and Pagan (1979).

Comparisons of effects across groups can be much more treacherous with logit than with standard linear regressions, (see Williams 2009), especially in the presence of heteroscedasticity. For this reason, since we are primarily interested in determining the effects of the variable Operator on the Answers, it is preferable to estimate separate models for the separate groups in order to avoid wrong parameter estimates. In the following discussion we briefly describe the models and the results for Experiment 1 and Experiment 2.

\section{Experiment 1}

As explained in Sect. 3, there are two groups of participants, 16 children and 10 adults.

\section{Children}

We first analyse the answers to the target QUDs as the dependent variable. We assume that the variable Operator is the fixed effect (plus an intercept that fixes a starting 
point), while the variables Subject and Item are random effects (see Barr et al. 2013 for a similar procedure). As explained above, the logit function relates the target QUD answer to the covariates as follows:

$$
\ln \frac{1-p_{s, i}}{p_{s, i}}=\beta_{0}+o \beta_{1}+B_{s}+B_{i}+\epsilon_{s, i} .
$$

Here and below, the data is analysed using R, making use of the glmer function. This function belongs to the package lme4, developed by Bates et al. (2011). We fit the model from Eq. (5) to the children's data using the following formula:

$$
\begin{array}{r}
\text { model.childrenA1 }=\text { glmer }(\text { targetQUD } \sim \text { operator }+(1 \mid \text { subject }) \\
+(1 \mid \text { item }), \text { family }=\text { binomial }, \text { data }=\text { childrenA } 1) .
\end{array}
$$

The results of this analysis are summarised below in Table 3. The analysis reveals a main effect of the variable Operator. Numerically, choosing a quantifier-question increases the value of the intercept, namely -0.4568 , by 3.6984 , raising the probability of a correct outcome to

$$
p=\frac{1}{1+e^{-3.2416}} \approx 96 \%
$$

An analogous analysis is performed for the answers to the wh-questions, which were used in the experiment to ensure that the QUD was attended to. The results are presented in Table 4. It is interesting to note that for this set of answers the main effect is due to the intercept, which gives a base-line for the probability of correct answers equal to:

$$
p=\frac{1}{1+e^{-1.5515}} \approx 83 \%
$$

Table 3 Best-fitting logistic regression of probability of correct answers for the operator (Experiment 1, Target QUD, subset children)

Generalized linear mixed model fit by maximum likelihood ['glmerMod']

\begin{tabular}{|c|c|c|c|c|c|}
\hline \multicolumn{6}{|c|}{ Random effects } \\
\hline Groups & Name & Variance & SD & & \\
\hline subject & (intercept) & 2.935 & 1.713 & & \\
\hline item & (intercept) & $\ll \mathrm{e}^{-5}$ & $2.439 \mathrm{e}^{-05}$ & & \\
\hline \multicolumn{6}{|c|}{ Fixed effects } \\
\hline & Estimate & SE & $\mathrm{z}$ value & $\operatorname{Pr}(>|z|)$ & \\
\hline (Intercept) & -0.457 & 0,593 & -0.770 & 0,441 & \\
\hline operatorQ & 3.698 & 0.954 & 3.839 & $0.124 \mathrm{e}^{-3}$ & $* * *$ \\
\hline
\end{tabular}

Family: binomial (logit)

Formula: TargetQUD operator $+(1 \mid$ subject $)+(1 \mid$ item $)$

Data: children1

Number of obs: 89 , group: subject, 16; item, 6 
Table 4 Best-fitting logistic regression of probability of correct answers for the operator (Experiment 1, Wh-questions, subset children)

Generalized linear mixed model fit by maximum likelihood ['glmerMod']

Family: binomial (logit)

Formula: wh-question $\sim$ operator $+(1 \mid$ subject $)+(1 \mid$ item $)$

Data: children 1

Number of obs: 89, group: subject, 16; item, 6

\begin{tabular}{|c|c|c|c|c|c|}
\hline \multicolumn{6}{|c|}{ Random effects } \\
\hline Groups & Name & Variance & SD & & \\
\hline Subject & (intercept) & $\ll \mathrm{e}^{-05}$ & $1.154 \mathrm{e}^{-05}$ & & \\
\hline Item & (intercept) & $5,526 \mathrm{e}^{-01}$ & $7.434 \mathrm{e}^{-01}$ & & \\
\hline \multicolumn{6}{|c|}{ Fixed effects } \\
\hline & Estimate & SE & $\mathrm{z}$ value & $\operatorname{Pr}(>|z|)$ & \\
\hline (Intercept) & 1.552 & 0.594 & 2.613 & $0.899 \mathrm{e}^{-2}$ & $* *$ \\
\hline operatorQ & 0.884 & 0.990 & 0.892 & 0.372 & \\
\hline
\end{tabular}

Signif. codes: ‘***' $\mathrm{p}<0.001$, “**’ $\mathrm{p}<0.01$, ‘*’ $\mathrm{p}<0.05$, ‘’ $\mathrm{p}<0.1$, ' ’ $\mathrm{p}<1$

\section{Adults}

In the first experiment, adults failed to give the correct answer 2 and 0 times, for target QUDs and wh-questions respectively, against 58 and 60 successful attempts. The results of the modelling of the Target QUDs are presented in Table 5 below. In light of the regression parameters, it is indeed safe to identify carelessness as the primary source of such errors, rather than trying to explain them in terms of dependence on covariates. We also believe it is not meaningful to analyse the wh-question adult data, because of the absence of wrong answers.

\section{Experiment 2}

In the second experiment, 32 children and 22 adults participated (see Sect. 4 in the main text for the details). The statistical analysis of the data is parallel to the first experiment.

\section{Children}

We model the answers to the dependent variables Target QUD and Wh-questions as done previously, using Eq. (5) as reference model. The results, followed by a short discussion, are presented below in Tables 6 and 7.

Let us start by looking at the probability of a correct answer for the Target QUDs. Similarly to Experiment 1 , while the value of the intercept $(-0.587)$ assigns the initial probability for a modal-type item, this is significantly increased when considering a quantifier $(+3.437)$. 
Table 5 Best-fitting logistic regression of probability of correct answers for the operator (Experiment 1, Target QUD, subset adults)

Generalized linear mixed model fit by maximum likelihood ['glmerMod']

Family: binomial (logit)

Formula: TargetQUD operator $+(1 \mid$ subject $)+(11 \mid$ item $)$

Data: adults1

Number of obs: 60 , groups: subject, 10; item, 6

Random effects

$\begin{array}{llll}\text { Groups } & \text { Name } & \text { Variance } & \text { SD } \\ \text { Subject } & \text { (intercept) } & \ll \mathrm{e}^{-5} & \ll \mathrm{e}^{-5} \\ \text { Item } & \text { (intercept) } & \ll \mathrm{e}^{-5} & \ll \mathrm{e}^{-5}\end{array}$

Fixed effects

\begin{tabular}{llllll} 
& Estimate & $\mathrm{SE}$ & $\mathrm{z}$ value & $\operatorname{Pr}(>|\mathrm{z}|)$ \\
(Intercept) & 3.367 & 1.017 & 3.311 & $0.931 \mathrm{e}^{-3}$ & *** \\
operatorQ & $\ll \mathrm{e}^{-5}$ & 1,438 & 0 & 1 \\
\hline
\end{tabular}

Signif. codes: ‘***' $\mathrm{p}<0.001$, ‘**’ $\mathrm{p}<0.01$, ‘*’ $\mathrm{p}<0.05$, ‘’ $\mathrm{p}<0.1$, ' ’ $\mathrm{p}<1$

Table 6 Best-fitting logistic regression of probability of correct answers for the operator (Experiment 2, Target QUD, subset children)

Generalized linear mixed model fit by maximum likelihood ['glmerMod']

Family: binomial (logit)

Formula: TargetQUD operator $+(1 \mid$ subject $)+(11 \mid$ item $)$

Data: children2

Number of obs: 92, groups: subject, 32; item, 6

Random effects

$\begin{array}{llll}\text { Groups } & \text { Name } & \text { Variance } & \text { SD } \\ \text { Subject } & \text { (intercept) } & 1.9338 & 1.3906 \\ \text { Item } & \text { (intercept) } & 0.2551 & 0.5051\end{array}$

Fixed effects

\begin{tabular}{llllll} 
& Estimate & $\mathrm{SE}$ & $\mathrm{z}$ value & $\operatorname{Pr}(>|\mathrm{z}|)$ \\
(Intercept) & -0.587 & 0.604 & -0.970 & 0.332 & \\
operatorQ & 3.437 & 1.172 & 2.933 & $0.336 \mathrm{e}^{-2}$ & ** \\
\hline
\end{tabular}

Signif. codes: ‘***' $\mathrm{p}<0.001$, '**' $\mathrm{p}<0.01$, ‘*’ $\mathrm{p}<0.05$, ‘’ $\mathrm{p}<0.1$, '|’ $\mathrm{p}<1$

First of all, the careful reader will notice that the formula adopted for the whquestions is different from the one used in Experiment 1; in particular, this is now equal to:

$$
\ln \frac{1-p_{s, i}}{p_{s, i}}=\beta_{0}+o\left(\beta_{1}+B_{0, i}\right)+B_{1, i}+\epsilon_{s, i} .
$$

Here we have introduced a random slope term $B_{0, i}$, which accounts for variation of answer outcomes dependent on single items. Moreover, to simplify the structure of the model we ignore the random effect caused by subjects, $B_{S}$, since in this case it 
Table 7 Best-fitting logistic regression of probability of correct answers for the operator (Experiment 2, Wh-questions, subset children)

\begin{tabular}{|c|c|c|c|c|c|}
\hline \multicolumn{6}{|c|}{$\begin{array}{l}\text { Generalized linear mixed model fit by maximum likeliho } \\
\text { Family: binomial (logit) } \\
\text { Formula: wh-question } \sim \text { operator }+(1+\text { operator|item }) \\
\text { Data: children2 } \\
\text { Number of obs: } 92 \text {, groups : subject, } 32 \text { : item, } 6\end{array}$} \\
\hline \multicolumn{6}{|c|}{ Random effects } \\
\hline Groups & $\begin{array}{l}\text { Name } \\
\text { (Intercept) }\end{array}$ & $\begin{array}{l}\text { Variance } \\
\ll \mathrm{e}^{-5}\end{array}$ & $\begin{array}{l}\mathrm{SD} \\
\ll \mathrm{e}^{-5}\end{array}$ & & \\
\hline Item & operatorQ. & 2.215 & 1.488 & & \\
\hline \multicolumn{6}{|c|}{ Fixed effects } \\
\hline & Estimate & SE & $\mathrm{z}$ value & $\operatorname{Pr}(>|z|)$ & \\
\hline (Intercept) & 1.692 & 0.411 & 4.113 & $3.91 \mathrm{e}^{-05}$ & $* * *$ \\
\hline operatorQ & $0,927 \mathrm{e}^{-2}$ & 1.106 & 0.008 & 0.993 & \\
\hline
\end{tabular}

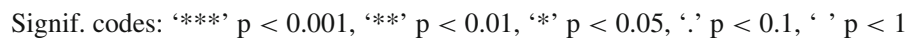

proves to be irrelevant. ${ }^{15}$ The results are shown in Table 7, and the coefficients of the random effects are listed in Table 8.

Since for children the variances for the random effect Subject during the target QUD part of the experiment are relatively large (see Tables 3,6), it seems to be necessary to examine the performance of the individual children. For instance, one might want to check whether some of the children are performing similar to adults. This can be assessed by looking at the distribution of the individual values of the random effects for the variable Subject. These are shown in Fig. 5 below. From the first graph we see that in Experiment 1 the random effects are well distributed across the whole range and average around zero. The absence of a second peak seems to indicate that the children performed "as children" on average, and the large variance only captures the fact that a few subjects performed more like adults whereas a few others performed less like them. The second graph, which depicts the subject random effect distribution for Experiment 2, shows two strong peaks and a smaller third. This seems to be due to the reduced number of questions posed to the children (three questions instead of six). However, the graphs confirm that the children behave consistently, and, if we look at their target responses together across conditions, there is no clear qualitative indication of a bimodal distribution in their behaviour.

\section{Adults}

Analogously to Experiment 1, in this experiment as well the adults accomplished the task successfully most of the times. In particular, we collected solely 1 wrong

15 When included in the model, its variance is $\ll 10^{-10}$. 
Table 8 Random intercepts and slopes for the variable Operator in Experiment 2, w.r.t. the Wh-questions

\begin{tabular}{lll}
\hline & \multicolumn{2}{l}{ Random effects } \\
\cline { 2 - 3 } & intercept & operatorQ \\
\hline 1 & $\ll \mathrm{e}^{-5}$ & $-2.642 \mathrm{e}^{-01}$ \\
2 & $\ll \mathrm{e}^{-5}$ & 1.452 \\
3 & $\ll \mathrm{e}^{-5}$ & -1.528 \\
4 & $\ll \mathrm{e}^{-5}$ & $\ll \mathrm{e}^{-5}$ \\
5 & $\ll \mathrm{e}^{-5}$ & $\ll \mathrm{e}^{-5}$ \\
6 & $\ll \mathrm{e}^{-5}$ & $\ll \mathrm{e}^{-5}$ \\
\hline
\end{tabular}

Note that while for items 4,5 , and 6 the effects are practically null, the probability of a correct response to the trial for items 2 and 3 is notably higher and lower than zero respectively
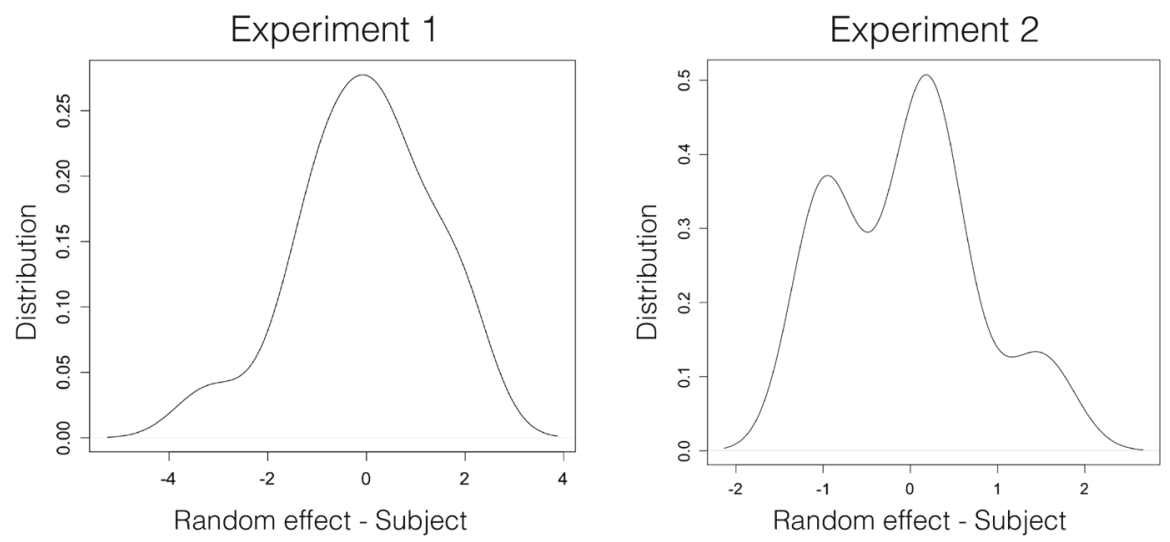

Fig. 5 Left-hand side distribution of random effect for the Subject variable in Experiment 1, Target QUD: 16 subjects (children). Right-hand side distribution of random effect for the Subject variable in Experiment 2, Target QUD: 32 subjects (children). A negative value of the random effect is assigned to a subject who underperforms, and vice versa for a positive value

answer for the target QUD, and 2 for the wh-questions, out of a total of 66 questions each. This confirms our previous assumption that adults are not affected by the use of modals versus quantifiers, and the few errors recorded must be a consequence of other factors, such as lack of attention. Nevertheless, for completeness we have analysed the relation between target QUD/wh-questions and the variable Operator using a simple linear model. The choice of dropping the generalised linear mixed model used so far was dictated by convergence problems, most likely due to the high number of subjects compared to the number of observations. The results are presented in Table 9; they confirm our predictions. 
Table 9 Best-fitting logistic regression of probability of correct answers for the operator (Experiment 2, Target QUD and Wh-questions, subset adults)

\section{Linear model}

Formula: TargetQUD operator

Data: adults2

Number of obs: 66, group: subject, 22; item, 6

\begin{tabular}{|c|c|c|c|c|c|}
\hline \multicolumn{6}{|c|}{ Fixed effects } \\
\hline & Estimate & SE & $\mathrm{t}$ value & $\operatorname{Pr}(>|\mathrm{t}|)$ & \\
\hline (Intecept) & 1 & $0,298 \mathrm{e}^{-1}$ & $3,353 \mathrm{e}^{+1}$ & $\ll \mathrm{e}^{-5}$ & $* * *$ \\
\hline operatorQ & $-0,606 \mathrm{e}^{-1}$ & $0.422 \mathrm{e}^{-1}$ & -1.437 & 0.156 & \\
\hline \multicolumn{6}{|c|}{ Linear mode } \\
\hline \multicolumn{6}{|c|}{ Formula: wh-questions $\sim$ operator } \\
\hline \multicolumn{6}{|c|}{ Data: adults2 } \\
\hline \multicolumn{6}{|c|}{ Number of obs: 66 , group: subject, 22;item, 6} \\
\hline \multicolumn{6}{|c|}{ Fixed effects } \\
\hline & Estimate & SE & t value & $\operatorname{Pr}(>|\mathrm{t}|)$ & \\
\hline (Intercept) & 1 & $0.214 \mathrm{e}^{-1}$ & $4.667 \mathrm{e}^{+1}$ & $\ll \mathrm{e}^{-5}$ & $* * *$ \\
\hline operatorQ & $-0.303 e^{-1}$ & $0.303 \mathrm{e}^{-1}$ & -1.00 & 0.321 & \\
\hline
\end{tabular}

Signif. codes: ‘***' $\mathrm{p}<0.001$, ‘**' $\mathrm{p}<0.01$, ‘*’ $\mathrm{p}<0.05$, ' ’ $\mathrm{p}<0.1$, ' ' $\mathrm{p}<1$

\section{Appendix 2: Target stories and items}

In this section, we provide English translations for all the target stories and items for both experiments.

\section{- Target story 1 (Quantifiers):}

"Jack, the photographer, and Fred, the caveman, are going to take photos of animals in the jungle. Two crocodiles and two elephants are walking by. Jack and Fred decide to try to take pictures of them. Fred tries first, however he doesn't manage to shoot any of them. Then it is Jack's turn. He manages to take photos of the elephants, but not of the crocodiles." Outcome: Jack the photographer managed to shoot the elephants but not the tigers. Fred on the other hand missed all the animals.

(46) QUD1 (Experiment 1):

Il fotografo ha fotografato tutti gli animali?

'Did the photographer shoot all of the animals?'

(47) QUD2 (Experiment 2):

C'è qualche animale che il fotografo non ha fotografato?

'Is there any animal that wasn't shot by the photographer?'

(48) Target:

Il fotografo non ha fotografato qualche animale

(True)

'The photographer didn't shoot some animal' 
(49) Wh-control:

QUD: Chi non ha fotografato nessuno?

'Who hasn't shot anyone?'

(50) Target:

Il fotografo.

'The photographer.'

(False)

- Target story 2 (Quantifiers):

"This story is about a Snow White and a dwarf who decide to play hide and seek with two Smurfs and two Roman soldiers. While Snow White is very good at this game, the dwarf is short-sighted and he is not that good. In fact, the dwarf finds no one. Snow White, instead, finds the Roman soldiers only."

Outcome: Snow White finds the Romans but not the Smurfs. The dwarf instead finds no one.

(51) QUD1 (Experiment 1):

Biancaneve ha trovato tutti i puffi?

'Did Snow White find all the smurfs?'

(52) QUD2 (Experiment 2):

C'è qualche puffo che Biancaneve non ha trovato?

'Is there anyone that wasn't found by Snow White?'

(53) Target:

Biancaneve non ha trovato qualcuno.

(True)

'Snow White hasn't found someone.'

(54) Wh-control:

QUD: Chi non ha trovato nessun puffo?

'Who hasn't found any smurf?'

(55) Target:

Biancaneve.

'Snow White.'

(False)

- Target Story 3 (Quantifiers):

"In this story there are two friends, Geronimo and Fred. Geronimo is a warrior and he loves riding animals. Fred, by contrast, has never tried. They see two cows and two horses and they decide to try riding them. Fred gives it a try but he is too frightened of falling down and he gives up. Then Geronimo's turn comes. He rides the cows first. Then, although he never failed before, this time he is feeling tired and he decides that he won't ride the horses."

Outcome: Geronimo rides the cows but not the horses. Fred rides no animal.

(56) QUD (Experiment 1):

Geronimo ha cavalcato tutti gli animali?

'Has Geronimo ridden all the animals?'

(57) QUD (Experiment 2):

Geronimo non ha cavalcato qualche animale?

'Has Geronimo not ridden some animal?' 
(58) Target:

Geronimo non ha cavalcato qualche animale.

(True)

'Geronimo hasn't ridden some animal.'

(59) Wh-control:

QUD (same for Experiment $1 \&$ 2):

Chi non ha cavalcato nessun animale?

'Who didn't ride any animal?'

(60) Target:

Geronimo.

'Geronimo.'

(False)

\section{- Target Story 4 (Modals):}

"Fred and Smurfette went to visit Papa Smurf at his faraway home. He lives very far away and they need to take a motorbike to get there. A motorbike is there for them to use. Smurfette says that the bike is too dangerous and, besides, she doesn't know how to drive it. Only Fred is tall enough to drive it. Fred is considering using it, but in the meantime a pilot comes and he offers Fred his car. Now Fred has two choices: he can take the bike or the car."

Outcome: Fred has two options, either driving the car or the motorbike. Smurfette, on the other hand, cannot drive anything.

(61) QUD1 (Experiment 1):

Fred deve guidare la moto?'

'Must Fred drive the bike?'

(62) QUD2 (Experiment 2):

Fred può non guidare la moto?

'Can Fred not drive the bike?'

(63) Target:

Fred può non guidare la moto.

'It is possible for Fred not to drive the bike.'

(True)

(64) Wh-control:

QUD: Chi non può guidare la moto?

'Who cannot drive the bike?'

(65) Target:

Fred.

(False)

'Fred.'

\section{- Target Story 5 (Modals):}

"There are a farmer and Smurfette and they need to feed a hippo. Smurfette has nothing to give to the hippo while the farmer only has carrots and he know that the hippo doesn't like them that much. In the meanwhile, Papa Smurf comes and he gives some turnips to the farmer. The farmer now has two options to feed the hippo."

Outcome: The farmer can feed the hippo with carrots or with turnips. Smurfette, on the other hand, has nothing to give him. 
(66) QUD1 (Experiment 1):

Il contadino deve dare le carote all'ippopotamo?

'Must the farmer give carrots to the hippo?'

(67) QUD2 (Experiment 2):

Il contadino può non dare le carote all'ippopotamo?

'Can the farmer not give carrots to the hippo?'

(68) Target:

Il contadino può non dare le carote all'ippopotamo.

'It is possible for the farmer not to give carrots to the hippo.'

(True)

(69) Wh-control:

QUD: Chi non può dare le carote all'ippopotamo?

'Who cannot give carrots to the hippo?'

(70) Target:

Il contadino.

'The farmer.'

(False)

- Target Story 6 (Modals):

"The caveman and the farmer decide to go into town but they find a huge log across the way. They need to remove it but they do not know how. Looking around, they see a truck and they think of using it. The caveman says that he doesn't know how to drive it and he can only try to lift the log with his own hands. However, the log is too heavy for him. The farmer instead knows how to drive the truck and he is about to use it to remove the log. In the meanwhile, the dwarf comes and he offers him his tractor."

Outcome: The farmer can use either the truck or the tractor to remove the obstacle.

(71) QUD1 (Experiment 1):

Il contadino deve usare il camion per spostare l'albero?

'Must the farmer use the truck to remove the log?'

(72) QUD2 (Experiment 2):

Il contadino può non usare il camion per spostare l'albero?

'Can the farmer not use the truck to remove the log?'

(73) Target:

Il contadino può non usare il camion.

(True)

'It is possible for the farmer not to use the truck.'

(74) Wh-control:

QUD: Chi non può usare il camion?

'Who cannot use the truck?'

(75) Target:

Il contadino.

'The farmer.'

(False) 


\section{References}

Allison, P. 1999. Comparing logit and probit coefficients across groups. Sociological Methods and Research 28: 186-208.

Baayen, H. 2008. Analysing linguistic data. A practical introduction to statistics using R. Cambridge: Cambridge University Press.

Baayen, R., D. Davidson, and D. Bates. 2008. Mixed-effects modeling with crossed random effects for subjects and items. Journal of Memory and Language 59: 390-412.

Barr, D., R. Levy, C. Scheepers, and H. Tily. 2013. Random effects structure for confirmatory hypothesis testing: Keep it maximal. Journal of Memory and Language 68: 255-278.

Bascelli, E., and S. Barbieri. 2002. Italian children's understanding of epistemic and deontic modal verbs dovere (must) and potere (may). Journal of Child Language 29: 87-107.

Bates, D., M. Maechler, and B. Bolker. 2011. lme4: Linear mixed-effects models using s4 classes. R package version 0.999375-42. http://cran.R-project.org/package=lme4.

Beaver, D., and B.Z. Clark. 2009. Sense and sensitivity. How focus determines meaning. Oxford: Oxford University Press.

Beghelli, F., and T. Stowell. 1997. Distributivity and negation: The syntax of each and every. In Ways of scope taking, ed. A. Szabolcsi, 71-107. Dordrecht: Kluwer.

Berwick, R.C. 1985. The acquisition of syntactic knowledge. Cambridge, MA: MIT Press.

Breslow, N., and D. Clayton. 1993. Approximate inference in generalized linear mixed models. Journal of the American Statistical Society 88: 9-25.

Breusch, T., and A. Pagan. 1979. A simple test for heteroscedasticity and random coefficient variation. Econometrica 47: 1287-1294.

Byrnes, J.P., and M.A. Duff. 1989. Young children's comprehension of modal expressions. Cognitive Development 4: 369-387.

Cardinaletti, A., and U. Shlonsky. 2004. Clitic positions and restructuring in Italian. Linguistic Inquiry 35(4): 519-557.

Crain, S., W. Ni, and L. Conway. 1994. Learning, parsing, and modularity, In Perspectives on sentence processing, ed. J.C. Clifton, L. Frazier and K. Rayner, 433-467. Hillsdale, NJ: Lawrence Erlbaum.

Crain, S., and R. Thornton. 1998. Investigations in universal grammar: A guide to experiments on the acquisition of syntax and semantics. Cambridge, MA: The MIT Press.

Fox, D. 1999. Reconstruction, binding theory, and the interpretation of chains. Linguistic Inquiry 30(2): 157-196.

Fox, D. 2000. Economy and semantic interpretation. Cambridge, MA: MIT Press.

Grice, P. 1975. Logic and conversation. In The Logic of Grammar, ed. D. Davidson and G. Harman, 64-75. Encino, CA: Dickenson.

Gualmini, A. 2004a. Some knowledge children don't lack. Linguistics 42: 957-982.

Gualmini, A. 2004b. The ups and downs of child language. New York: Routledge.

Gualmini, A., S. Hulsey, V. Hacquard, and D. Fox. 2008. The Question-Answer Requirement for scope assignment. Natural Language Semantics 16: 205-237.

Gualmini, A., and V. Moscati. 2009. The early steps of modal and negation interactions: Evidence from child Italian. In Romance Language and linguistic theory. Selected papers from 'Going Romance' Amsterdam 2007, 131-144. Amsterdam: John Benjamins.

Gualmini, A., and B. Schwarz. 2009. Solving the learnability problems in the acquisition of semantics. Journal of Semantics 26: 185-215.

Hamblin, C. 1973. Questions in Montague grammar. Foundations of Language 10(1): 41-53.

Hirst, W., and J. Weil. 1982. Acquisition of epistemic and deontic meaning of modals. Journal of Child Language 9: 659-666.

Jaeger, T.F. 2008. Categorical data analysis: Away from Anovas (transformation or not) and towards logit mixed models. Journal of Memory and Language 59: 434-446.

Krämer, I. 2000. Interpreting indefinites. PhD thesis, Max Planck Institute for Psycholinguistics, Nijmegen. Lidz, J., and J. Musolino. 2006. On the quantificational status of indefinites: The view from child language. Language Acquisition 13(2): 73-102.

May, R. 1985. Logical Form: Its structure and derivation. Cambridge, MA: MIT Press.

Mayr, C., and B. Spector. 2013. Not too strong! Generalizing scope economy. In Proceedings of Sinn und Bedeutung 14, 305-321. 
Merchant, J. 2001. The syntax of silence: sluicing, islands, and the theory of ellipsis. Oxford: Oxford University Press.

Mood, C. 2010. Logistic regression: Why we cannot do what we think we can do, and what we can do about it. European Sociological Review 26(1): 67-82.

Moscati, V. 2008. Strength and weakness in children's interpretation of modals. In Proceedings of the 9th Tokyo conference on Psycholinguistics, ed. Y. Otsu, 103-119. Tokyo: Hituzi Syobo.

Moscati, V. 2011. Discourse under control in ambiguous sentences. In Experimental pragmatics and semantics, ed. J. Meibauer and M. Steinback, 63-78. Amsterdam: John Benjamins.

Moscati, V. 2013. Why children prefers impossible worlds. Lingue e Linguaggio XI I(2): 223-248.

Moscati, V., and S. Crain. 2014. When negation and epistemic modality combine: the role of information strength in child language. Language and learning development 10: 345-380.

Moscati, V., and A. Gualmini. 2008. More facts that Isomorphism cannot explain. In Proceedings of SALT 17, 202-209. Ithaca, NY: CLC Publications.

Musolino, J. 1998. Universal Grammar and the acquisition of semantic knowledge. PhD thesis, University of Maryland.

Musolino, J., S. Crain, and R. Thornton. 2000. Navigating negative quantificational space. Linguistics 38: $1-32$.

Musolino, J., and J. Lidz. 2003. The scope of isomorphism: Turning adults into children. Language Acquisition 11(4): 277-291.

Musolino, J., and J. Lidz. 2006. Why children aren't universally successful with quantification. Linguistics 44: 817-852.

Noveck, I. 2001. When children are more logical than adults: experimental investigations of scalar implicatures. Cognition 78(8): 165-188.

Noveck, I., S.A. Ho, and M. Sera. 1996. Children's understanding of epistemic modals. Journal of Child Language 23(3): 621-643.

Portner, P. 2009. Modality. Oxford: Oxford University Press.

Rizzi, L. 1982. Issues in Italian syntax. Dordrecht: Foris Publications.

Roberts, C. 2004. Context in dynamic interpretation. In Handbook of pragmatics, ed. L.R. Horn and G. Ward, 197-220. Malden, MA: Blackwell.

von Fintel, K. 1994. Restrictions on quantifier domains. PhD thesis, University of Massachusetts at Amherst.

Williams, R. 2009. Using heterogeneous choice models to compare logit and probit coefficients across groups. Sociological Methods and Research 37: 531-559. 